\title{
How to get your paper published: Confessions of an editor
}

\author{
Lloyd R Sutherland MD MSc FRCPC FACP
}

P ublications are the gold standard of academic life. In every stage of the process, from entering medical school to promotion to full-time Professor, the publications of the candidate play an important role in assessing his or her career path in passing through the phases of academic life. So, keep the following 10 tips in mind when you decide to publish your manuscript.

\section{Preparing the manuscript}

First, most successful writers would agree that allowing time for rewriting is the key to success in having your work accepted. A Iways allow yourself sufficient time for rewriting the manuscript several times. A Ithough M ozart reportedly wrote many of his major symphonies without revising a single note, most writers will write three or four versions before the final version is submitted. Everyone has his or her own approach for writing the first draft. Some may concentrate on using the traditional structure to develop the manuscript while others write a structured abstract or do the results section first.

Second, consider using figures instead of tables. 0 ne picture is indeed better than a thousand words, but play fair with the reader. There are lots of tricks one can use to minimize or emphasize a finding, such as by simply changing the scales on the $x$ - and $y$-axes.

Finally, ask one or two colleagues to read an early draft. If possible, involve someone not directly in the field that can point out when you lapse into jargon. For many journals, the readership may be interested in your topic, but it must be simplified for them. Limit the discussion to no more than three pages. Focus on the major findings.

\section{Selecting the journal}

Give careful thought to where you wish to publish your findings. W ith the availability of electronic searching, it is likely that those who want to find your research will find it, but the prestige of the journal (usually related to the impact factor) determines whether the currency of this paper will be viewed as a bronze, silver or gold. Review the table of contents to see if the journal has published similar papers in the past.

Knowing the research interests of the editor may also be hel pful. In the case of one of my own papers, I believe the edi- tor was sympathetic because he had an interest in the area as well. In another situation, however, I was tempted not to send a meta-analysis to an editor because I heard he did not consider the analysis an appropriate topic for his journal. O ne of the other authors wanted to submit to the journal regardless and the paper was accepted.

\section{Submitting the manuscript}

M ake sure you followed all of the instructions to authors. Your manuscript is valuable; send the manuscript by courier or electronically.

Consider the strategic use of the letter of transmission accompanying the manuscript. Is there a rival unit who might wish you ill? M ost editors will at least consider not using someone identified as being biased against the work as a reviewer.

\section{R esponding to reviewers}

Read the letter from the editor carefully. "A Ithough I cannot accept the current version of your manuscript, we would be happy to see another version. I enclose details as how to reformat the manuscript" is a letter of acceptance, not rejection.

Before you begin to respond to the reviewers ask yourself "how badly do I want this paper published in this journal?" You may feel that the reviewers have it all wrong, but until you satisfy them you won't get the paper published. In my experience, editors are willing to negotiate on some revisions and not on others. If a reviewer cites an authority in the field as being an important addition to the manuscript, then take that advice. Save your disputes for something more crucial rather than if someone would be cited in a paper.

If the article is rejected by the journal use the comments to revise the paper before you send it out again. Don't submit the paper unchanged. I have been asked on several occasions to review the same manuscript unchanged from the original. I sometimes send a photocopy of my review back!

Good luck!

Presented at the $C$ anadian D igestive $D$ iseases W eek conference, Banff, A lberta, February 19-25, 2003 


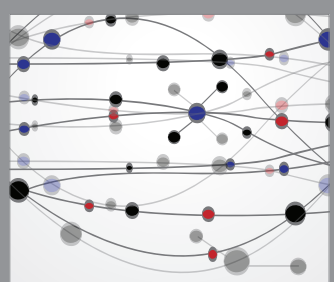

The Scientific World Journal
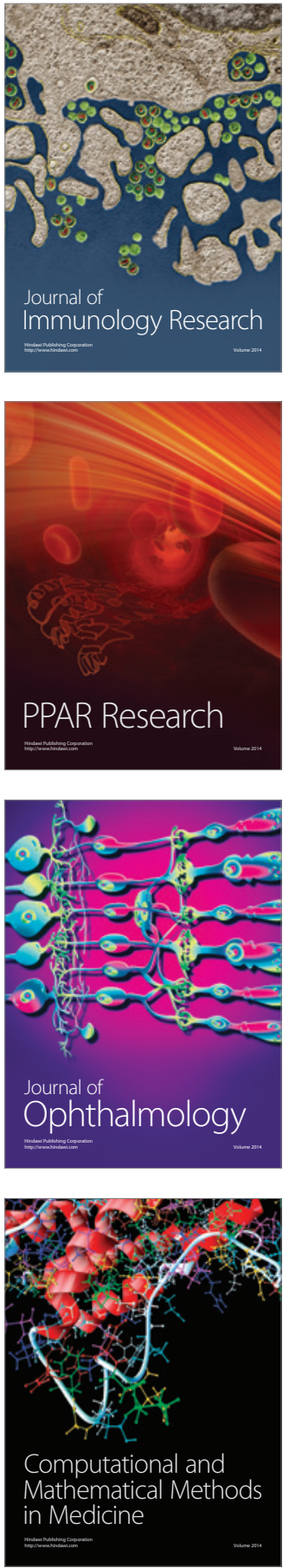

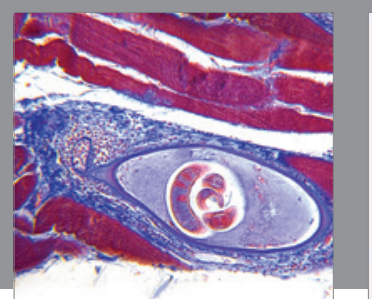

Gastroenterology Research and Practice

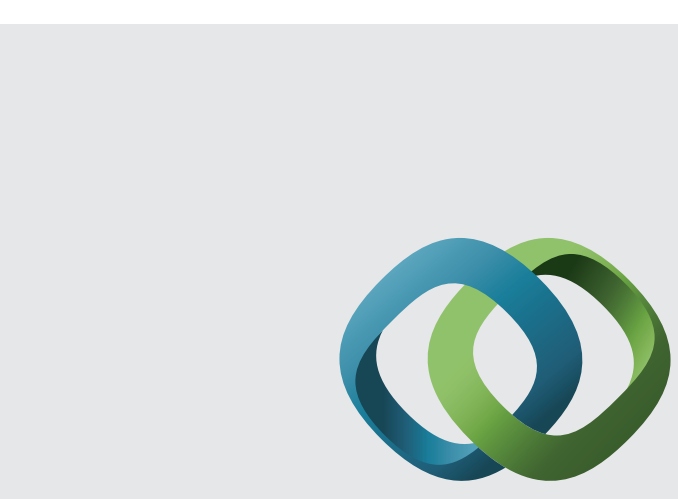

\section{Hindawi}

Submit your manuscripts at

http://www.hindawi.com
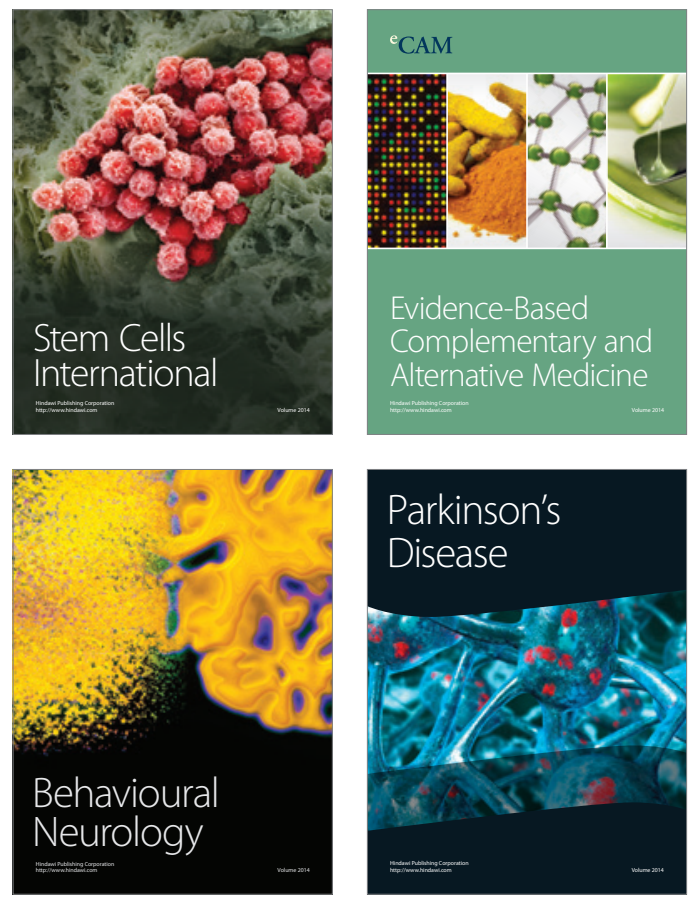
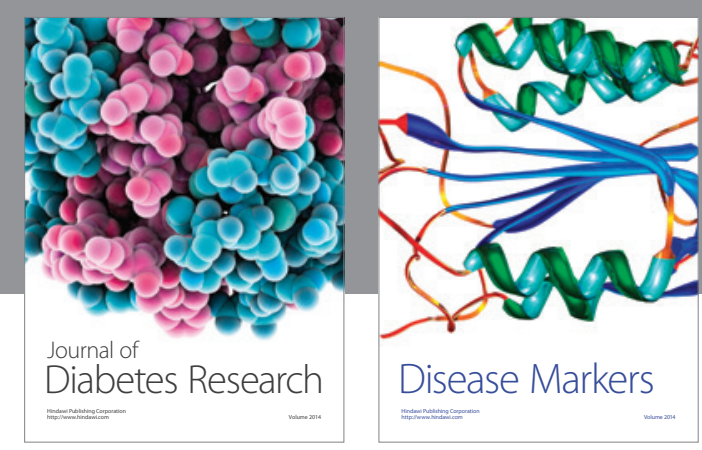

Disease Markers
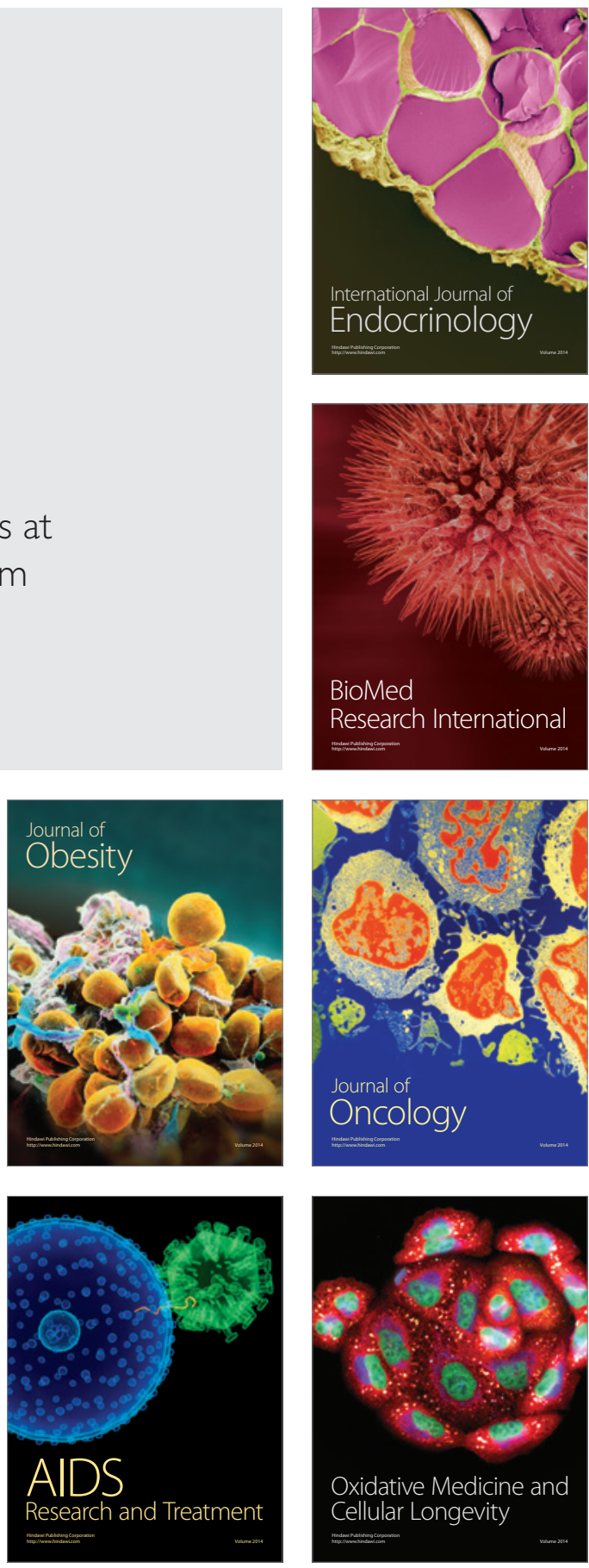